\title{
New Practical Aspects of Sweet Syndrome
}

\author{
Tejas P. Joshi ${ }^{1}$ (1) - Sarah K. Friske ${ }^{1}$ - David A. Hsiou ${ }^{1}$ - Madeleine Duvic ${ }^{2}$
}

Accepted: 19 January 2022 / Published online: 14 February 2022

(c) The Author(s), under exclusive licence to Springer Nature Switzerland AG 2022

\begin{abstract}
Sweet syndrome (SS), or acute febrile neutrophilic dermatosis, is an inflammatory, non-infectious skin reaction characterized clinically by tender, erythematous papules/plaques/pustules/nodules commonly appearing on the upper limbs, trunk, and head and neck; histologically, SS is characterized by dense neutrophilic infiltrate in the dermis. SS is accompanied by fever; an elevation of inflammatory markers (e.g., erythrocyte sedimentation rate, C reactive protein) in serum may also be observed. Although most cases of SS are idiopathic, SS also occurs in the setting of malignancy or following administration of an associated drug. SS has also been reported in association with pregnancy and a burgeoning list of infectious (most commonly upper respiratory tract infections) and inflammatory diseases; likewise, the litany of possible iatrogenic triggers has also grown. Over the past several years, a wider spectrum of SS presentation has been realized, with several reports highlighting novel clinical and histological variants. Corticosteroids continue to be efficacious first-line therapy for the majority of patients with SS, although novel steroid-sparing agents have been recently added to the therapeutic armamentarium against refractory SS. New mechanisms of SS induction have also been recognized, although the precise etiology of SS still remains elusive. Here, we catalogue the various clinical and histological presentations of SS, summarize recently reported disease associations and iatrogenic triggers, and review treatment options. We also attempt to frame the findings of this review in the context of established and emerging paradigms of SS pathogenesis.
\end{abstract}

\section{Introduction}

In 1964, Dr Robert Douglas Sweet described an "acute febrile neutrophilic dermatosis" in eight women who presented with the four cardinal features of "fever, neutrophil polymorphonuclear leukocytosis of the blood, raised painful plaques on the limbs, face and neck and histologically a dense dermal infiltration with mature neutrophil polymorphs." Although Dr Sweet noted the reaction resembled erythema multiforme, he surmised it to be a unique entity hitherto undescribed. He would subsequently become eponymous for the disease, and the acute febrile neutrophilic dermatosis he described would become known as Sweet syndrome (SS) [1].

Now, more than half a century following Dr Sweet's seminal case series, our understanding of SS has expanded considerably. Various clinical and histological subtypes

Tejas P. Joshi

tejas.joshi@bcm.edu

1 School of Medicine, Baylor College of Medicine, 1 Baylor Plaza, Houston, TX 77030, USA

2 Department of Dermatology, University of Texas, MD Anderson Cancer Center, Houston, TX, USA

\section{Key Points}

A wide spectrum of Sweet syndrome (SS) has now been realized, with bullous SS, cellulitis-like SS, necrotizing SS, and neutrophilic dermatosis of the dorsal hands being described as clinical variants. Cryptococcoid, histiocytoid, and subcutaneous subtypes have also been reported as histologic variants.

SS has been described in the setting of various infectious diseases, malignancies, autoimmune processes, as well as, paradoxically, immunodeficient states. A number of iatrogenic triggers for SS have also been recently added to the literature.

SS is typically exquisitely responsive to steroid treatment. Second-line therapies should be personalized according to patient co-morbidities, past medical history, and preference.

A canonical dogma to conceptualize SS pathogenesis likely does not exist. Rather, SS pathogenesis appears to be multifactorial, a product of external chemical and physical insults (pathergy), host immune dysregulation (due to autoimmunity or malignancy), and/or predisposing genetic elements. 
have been established, additional disease associations have been described, and a number of therapeutic options have been reported. Here, we discuss these recent findings to provide a cohesive picture of SS that will facilitate the clinical diagnosis and management of SS. We also attempt to frame the findings of this review in the context of established and emerging paradigms of SS pathogenesis.

\section{Methods}

We performed a literature search using PubMed with the search term 'Sweet syndrome.' As a comprehensive review of SS was published in 2018 by Nelson et al. [2], we focused on articles published from 2019 to October 2021, although we also include some articles published prior to 2018 to provide context. We excluded commentaries, editorials, and articles not published in the English language. Case studies and case series were included.

We assessed the quality of studies reporting drug-induced SS using the Naranjo Drug Reaction Probability Scale (Supplementary Table 1 , see electronic supplementary material [ESM]), which evaluates the likelihood of an adverse drug reaction (ADR) on a scale of 1 to 13, in which a score of 1-4 indicates a 'possible' ADR, a score of 5-8 indicates a 'probable' ADR, and a score of 9-13 indicates a 'definite' ADR [3]. Additionally, we assessed the quality of studies reporting an effective response of SS to a particular treatment using the Tool for evaluating the methodological quality of case reports and case series proposed by Murad and colleagues, which evaluates case reports and cases series across four domains: selection, ascertainment, causality, and reporting (Supplementary Table 2, see ESM) [4]. All studies were assessed by two independent reviewers (either TPJ and SKF or TPJ and DAH); conflicts were resolved by discussion.

\section{Epidemiology}

The true incidence of SS in the general population remains to be established, although SS is considered to be a rare phenomenon. Likely owing to its rarity, studies of SS are largely limited to case reports and small case series. In 1993, Cohen and Kurzrock pooled reported cases of SS to elucidate the epidemiology of SS. They reported the male : female ratio of SS to vary according to etiology, with the female : male ratio of idiopathic SS to be $4: 1$, of hematologic malignancy associated SS to be 1:1, of solid tumor associated SS to be approximately 1.4:1, and of drug-induced SS to be approximately 2.4:1 [5]. More recent retrospective studies have reported roughly equal female:male distribution in non-malignancy-associated SS as well as malignancy associated SS [6-8]. SS has also been reported to have no racial predilection, although neuro-Sweet disease, a variant of SS presenting with neurological symptoms, has been most commonly noted in Japanese patients [9].

SS usually presents in individuals in their sixth decade of life $[7,10,11]$. Occurrence of SS in the pediatric population is rare (with an estimated 5-8\% of cases of SS being reported in children [12]), although several cases of pediatric SS have been recently reported in literature [13-20]. In a 2019 French study of 10 pediatric SS patients, the investigators reported a median age of 2.7 years at presentation and a female to male ratio of 2:3. The lesions were distributed primarily on the lower ( $8 / 10$ patients) and upper extremities (7/10 patients). The investigators noted that nine of the ten patients had extracutaneous involvement and that six of the ten patients had an atypical variant of SS [21]. Thus, it is possible that pediatric SS manifests differently than adult SS, although further studies are needed to more definitively establish the presentation of pediatric SS.

SS has also been reported, albeit rarely, during pregnancy. The etiology of pregnancy-associated SS is unclear, although it has been speculated that hormonal changes during pregnancy are in some capacity immunomodulatory, thereby contributing to pregnancy-associated SS. Two cases of pregnancy-associated SS have been recently reported [22, 23].

\section{Diagnostic Criteria, Clinical and Histological Subtypes, Extracutaneous Manifestations, and Differential Diagnosis}

SS exists on the spectrum of neutrophilic dermatoses that include Behçet's disease and pyoderma gangrenosum (PG). Classical SS presents as tender, erythematous papules/ plaques/pustules/nodules and is accompanied by fever and frequently elevated neutrophil count. A recent case series of eight SS patients showed immunohistochemical staining with interleukin (IL)-17E and inducible nitric oxide synthase (iNOS) to be expressed in the epidermis of SS patients; however, larger studies are needed to validate if these markers are consistently expressed [24]. Typically, the lesions involve the upper extremities, face, and neck, although other sites, albeit less frequently, can be affected. Recently, a case of SS limited to the acral surfaces [25] and another case of SS involving the male genitalia have been reported [26]. Histologically, SS presents with diffuse neutrophilic infiltration of the upper dermis which may display karyorrhexis; marked papillary dermal edema can also be observed; however, leukocytoclastic vasculitis should not be observed. Leukemic 'bystander' cells may be variably present. Dermoscopic findings are non-specific, 
but reveal focal or diffuse pale regions against a pinkish background. Bluish-purple areas may also be noted, and are a reflection of erythrocyte extravasation into the dermis. Blood vessels are usually not visualized as they are obscured by dermal edema [27].

In the past few decades, numerous variants of SS, both clinical and histologic, have been described. Furthermore, SS has been reported to assume many extracutaneous manifestations, some of which can be fatal. We catalogue these recently reported variants and also note the sites of extracutaneous SS involvement.

\subsection{Diagnostic Criteria}

In 1986, Su and Liu first proposed diagnostic criteria for classical SS [28] that were then modified by von den Driesch [29] in 1994. The diagnostic criteria proposed by von den Driesch require the fulfillment of both major criteria and two of the four minor criteria listed in Table 1 [29]. Of note, we point out that the von den Driesch criteria require neutrophilic infiltrate to diagnose SS; however, several reports have diagnosed SS despite the lack of a predominant neutrophilic infiltrate [30-32]. We recommend against the use of SS as an umbrella term to describe entities that present histologically with eosinophilic or lymphocytic infiltrate, despite presenting clinically as SS.

In 1996, diagnostic criteria for drug-induced SS were established by Walker and Cohen; all criteria must be met to satisfy a diagnosis of drug-induced SS (Table 2) [33].

\subsection{Clinical Variants}

\subsubsection{Bullous Sweet Syndrome}

Bullous SS is an uncommon variant of SS that can present as flaccid or tense blisters on the acral surfaces, face, extremities, and trunk. On microscopic examination, separation of the dermal-epidermal junction can be appreciated
[34-36]. The exact incidence of bullous SS is unknown, although up to $30 \%$ of patients with SS may present with bullae [7].

Like classical SS, bullous SS can occur in patients with non-contributory past medical history, or it can also present in patients with chronic disease. Recently, a case of bullous SS without any underlying disease has been presented [34]; bullous SS has also been reported in the setting of acute myeloid leukemia (AML) and active [35] and inactive [36] ulcerative colitis. A case of bullous SS in a 10-year-old girl with a previous upper respiratory tract infection has also been described [37]. Two cases of bullous SS presenting with positive antineutrophil cytoplasmic antibodies (ANCA) without underlying vasculitis have also been described [38].

\subsubsection{Cellulitis-Like Sweet Syndrome}

Cellulitis-like SS is a rare SS variant characterized by tender, erythematous, edematous lesions and can be indistinguishable from bacterial cellulitis. However, cultures of cellulitislike SS are negative for pathogenic organisms, and antibiotic treatment is unable to induce lesion remission. Three recent cases of cellulitis-like SS have been reported, and the authors of all cases concede that the diagnosis of cellulitislike SS is challenging [39-41]. Thus, clinicians should maintain a high index of suspicion for SS when a cellulitis-like clinical picture presents with negative bacterial cultures and displays no response to antibiotic therapy.

\subsubsection{Necrotizing Sweet Syndrome}

The term 'necrotizing Sweet syndrome' was coined in 2012 by Kroshinsky et al., who described three patients presenting with rapidly progressive erythematous, edematous cutaneous lesions with necrotic involvement of underlying soft tissues. The patients were initially diagnosed with necrotizing fasciitis; however, as microbial cultures were negative in all cases, and histopathology was consistent with SS, a

Table 1 von den Driesch criteria for diagnosis of Sweet syndrome. Both the major criteria and two of the four minor criteria must be met for diagnosis [29]

\begin{tabular}{ll}
\hline Major criteria & Minor criteria \\
\hline $\begin{array}{l}\text { 1. Abrupt onset of painful erythematous plaques or nodules } \\
\begin{array}{l}\text { 2. Histopathologic evidence of a dense neutrophilic infiltrate without } \\
\text { evidence of leukocytoclastic vasculitis }\end{array}\end{array}$ & $\begin{array}{l}\text { 1. Pyrexia }>38{ }^{\circ} \mathrm{C} \\
\text { 2. Association with an underlying hematological or visceral malig- } \\
\text { nancy, inflammatory disease, or pregnancy, or preceded by an upper } \\
\text { respiratory or gastrointestinal tract infection or vaccination }\end{array}$ \\
& $\begin{array}{l}\text { 3. Excellent response to systemic corticosteroids or potassium iodide } \\
\text { 4. Elevation of three of the four laboratory values: } \\
\text { (i) erythrocyte sedimentation rate }>20 \mathrm{~mm} / \mathrm{h}\end{array}$ \\
& $\begin{array}{l}\text { (ii) positive } \mathrm{C}-\text { reactive protein } \\
\text { (iii) leukocyte count }>8000\end{array}$ \\
& (iv) neutrophils $>70 \%$
\end{tabular}


Table 2 Walker and Cohen criteria for diagnosis of drug-induced Sweet syndrome. All criteria must be met for diagnosis [33]

\begin{tabular}{ll}
\hline Criterion no. & Criteria \\
\hline 1 & Abrupt onset of painful erythematous plaques or nodules \\
2 & Histopathologic evidence of a dense neutrophilic infiltrate without evidence of leukocytoclastic vasculitis \\
3 & Pyrexia $>38^{\circ} \mathrm{C}$ \\
4 & Temporal relationship between drug ingestion and clinical presentation or temporally related recurrence \\
5 & after oral challenge \\
\hline
\end{tabular}

diagnosis of SS was favored over necrotizing fasciitis [42]. In 2019, Sanchez et al. reviewed the 14 published cases of necrotizing SS, and grouped this variant under the entity 'necrotizing neutrophilic dermatoses' [43].

More recently, seven additional cases of necrotizing SS have been added to the literature [44-48]. In all reports, the authors emphasize the need to distinguish necrotizing SS from necrotizing fasciitis, as the surgical debridement of necrotizing SS can lead to further exacerbation of SS and involvement of additional tissue. Four of these recently reported cases regressed completely following steroid treatment [44, 46-48], two responded completely to dapsone and steroid combination therapy [44], and one patient experienced lesion regression following discontinuation of bortezomib (the putative offending agent) and steroid treatment [45].

\subsubsection{Neutrophilic Dermatosis of the Dorsal Hands and Generalized Pustular Sweet Syndrome}

Neutrophilic dermatosis of the hands (NDDH) is another subtype of SS that presents as indurated, painful, erythematous plaques admixed with possible ulcers and pustules; as the name suggests, NDDH involves the dorsal hands. Such an entity was first recognized by Strutton et al. in 1995 [49], and assigned the nomenclature "neutrophilic dermatosis of the dorsal hands' by Galaria et al. in 2000 [50].

In 2019, Micallef et al. reviewed 123 published cases of NDDH. Based on their collation of reported cases in literature, the investigators determined NDDH to present at a mean age of 62.1 years and noted NDDH to have a slight penchant for females. The majority of patients $(78 \%)$ had bilateral hand involvement. Furthermore, $40 \%$ of patients had underlying disease, with the most common associations being hematological dyscrasias (14.3\%), solid organ malignancies (15.5\%), and recent infections (10.6\%). The investigators noted the histopathology as well as the clinical lesions of NDDH to be consistent with those of classical SS [51].

More recently, six additional reports of NDDH have been added to the literature [52-55]. One of these reports attributed NDDH to the Koebner phenomenon, as NDDH appeared following mechanical trauma [55].

Some authors consider generalized pustular SS, a clinical variant with disseminated pustular lesions, to be a subtype of NDDH [56]. However, we suggest that generalized pustular SS should be considered an independent entity, and not as a subtype of NDDH.

\subsection{Histological Variants}

\subsubsection{Cryptococcoid Sweet Syndrome}

The first reports of cryptococcoid SS are credited to Ko et al., who described this rare histologic variant in 2013 [57]. The term 'cryptococcoid Sweet syndrome' itself was formally introduced in 2017 by Wilson et al. [58]. Microscopic examination of cryptococcoid SS reveals vacuolated mononuclear cells with the presence of basophilic yeastlike bodies, a presentation compatible with a diagnosis of cryptococcosis. However, periodic acid Schiff (PAS) stain of the biopsy fails to reveal fungal elements, and the cutaneous lesions of cryptococcoid SS do not remit with anti-fungal therapy. Cryptococcoid SS appears to be a rare phenomenon, as only four cases of cryptococcoid SS have recently been reported. Of note, all have been associated with ANCA positivity, although only one was present in the setting of primary vasculitis [59]. It is unclear if the association between ANCA positivity and cryptococcoid SS is coincidental or causal.

\subsubsection{Histiocytoid Sweet Syndrome}

Histiocytoid SS is characterized by the presence of immature neutrophils in the dermis that resemble histiocytes; the entity was first described by Requena et al. in 2005. Microscopic examination of histiocytoid SS reveals exuberant infiltrate of immature neutrophils; immunohistochemical staining is positive for cluster of differentiation 68 (CD68) and myeloperoxidase. Since the publication of the disease defining case series by Requena et al., over 200 cases of histiocytoid SS have been reported [60]. 
In 2020, Haber et al. performed a systematic review of all published cases of histiocytoid SS to better characterize this histologic variant. The investigators reported histiocytoid SS to have a fairly equal (1.11:1) female:male ratio. They additionally noted extracutaneous involvement to be a relatively rare occurrence. Moreover, histiocytoid SS, compared with classical SS, was found to be associated with a higher risk of underlying malignancy [61].

There has been some controversy over whether histiocytoid SS overlaps with leukemia cutis. However, in 2017 Alegría-Landa et al. performed immunohistochemical studies on 33 patients with histiocytoid SS to unequivocally show that the cells in histiocytic SS were of myeloid, not lymphoid, lineage. The study also failed to reveal histiocytoid SS being more frequently associated with malignancy compared with classical SS [62], a result inconsistent with the systematic review by Haber et al [61]. However, as malignancy-associated cases of histiocytoid SS may be overrepresented in literature due to novelty, the pooled analysis by Haber et al. may artificially create an association between malignancy and histiocytoid SS where such an association may not veritably exist [61]. Further studies are warranted to elucidate whether histiocytoid SS is more likely to be associated with malignancy than classical SS.

It is unclear if the treatment for histiocytoid SS should differ from those for other SS variants. Several cases of histiocytoid SS have been shown to regress completely with steroid treatment [63-65], while one case of histiocytoid SS refractory to steroid therapy has been recently described [66]. Once again, larger studies of patients with histiocytoid SS would help elucidate the best treatment options for this variant.

\subsubsection{Subcutaneous Sweet Syndrome}

Subcutaneous SS presents with panniculitis and neutrophilic invasion of the subcutaneous adipose tissue. In an 83-patient retrospective study, $11 \%$ of patients were reported to have the subcutaneous variant of SS [7]. Subcutaneous SS has typically been reported to present with hematological dyscrasias, although it is unclear if the high prevalence of subcutaneous SS in the setting of hematological dyscrasias is simply due to the novelty of presenting a case of malignancy-associated subcutaneous SS. Indeed, of the three recently reported cases of subcutaneous SS, two have been in the setting of hematologic malignancy (AML [19] and myelodysplastic syndrome [67]) and one has been reported in association with Behçet's disease [68]. Larger retrospective studies are needed to assess a possible association between subcutaneous SS and hematological malignancy, as case reports do not furnish the highest level of evidence to answer this question.

\subsubsection{Other Histologic Patterns}

Other atypical histologic patterns have also been reported in the literature. While neutrophil predominance is the histopathologic hallmark of SS, cases of SS with a predominant eosinophilic [32] and lymphocytic infiltrate [30, 31] have been described. In cases of eosinophil predominant SS [32], a complete blood count may be indicated to rule out eosinophilic dermatosis of hematologic malignancy. The authors' position is that cases without neutrophil predominance should not be classified as SS.

Recently, a novel subtype of SS, normolipemic xanthomized Sweet syndrome, was reported by Kamimura et al. Microscopic examination of this unusual case revealed CD163-positive foam cells to accompany dense neutrophilic infiltrate extending into the deep dermis [69]. Further reports may aid in further characterization of this variant.

We summarize the recently reported clinical and histologic subtypes in Table 3. Of note, we emphasize that there is overlap between the clinical and histological entities described. For example, So et al. described a case of cellulitis-like SS with histiocytoid histology. In such instances, where both the histology and clinical presentation differ from the classical presentation of SS, it may be appropriate to refer to the case by both its clinical and histological presentation (e.g., 'histiocytoid cellulitis-like Sweet syndrome') [70].

Additionally, SS lesions can display both spatial and temporal heterogeneity. Pătraşcu et al. recently reported an interesting case of SS in which the histological presentation of SS changed over time. At initial presentation, the patient presented with histiocytoid SS; at 3-year follow-up, the lesions assumed the prototypic neutrophilic infiltrate [71]. Furthermore, in August 2021, Burke et al. presented a case of SS with two co-exiting SS variants: subcutaneous SS, present on the patient's right shoulder, and histiocytoid SS, present on the patient's left shin [72]. These cases suggest that diagnosis of one variant of SS is not mutually exclusive with that of another, and leads us to speculate that the subtypes of SS perhaps exist on a continuum. In such situations where the clinicopathologic picture is ambiguous, it may be reasonable to refer to the condition as 'neutrophilic dermatosis, unspecified.' Furthermore, considering the novel 2021 report of normolipemic xanthomized SS, it is likely that the gamut of SS presentation is wide and subject to evolution.

\subsection{Extracutaneous Involvement}

Although SS is usually limited to the skin, it can rarely involve extracutaneous sites. Such extracutaneous involvement has been referred to as 'neutrophilic disease,' a term coined by Wallach and Vignon-Pennamen [73]. Recognition 
Table 3 Clinical and histological variants of Sweet syndrome

\begin{tabular}{|c|c|c|}
\hline Variants & Description & References \\
\hline \multicolumn{3}{|l|}{ Clinical } \\
\hline Prototypic clinical presentation & $\begin{array}{l}\text { Tender, erythematous nodules/papules/plaques located on the upper extremities, } \\
\text { face, and neck }\end{array}$ & [1] \\
\hline Bullous SS & Flaccid or tense blisters on the acral surfaces, extremities, the trunk, and face & [34-38] \\
\hline Cellulitis-like SS & $\begin{array}{l}\text { Tender, erythematous, edematous lesions that are indistinguishable from bacte- } \\
\text { rial cellulitis; cultures do not reveal bacteria }\end{array}$ & [39-41] \\
\hline Necrotizing SS & $\begin{array}{l}\text { Rapidly progressive erythematous, edematous cutaneous lesions with necrotic } \\
\text { involvement of underlying soft tissues; must rule out necrotizing fasciitis }\end{array}$ & {$[42,44-48]$} \\
\hline Neutrophilic dermatosis of the dorsal hands & $\begin{array}{l}\text { Indurated, painful, erythematous plaques admixed with possible ulcers and } \\
\text { pustules involving the dorsal hands }\end{array}$ & {$[30,31,49-56]$} \\
\hline \multicolumn{3}{|l|}{ Histological } \\
\hline Prototypic histological presentation & $\begin{array}{l}\text { Diffuse neutrophilic invasion into the upper dermis; infiltrated neutrophils } \\
\text { may display karyorrhexis; IHC reveals IL-17E and iNOS expression in the } \\
\text { epidermis }\end{array}$ & {$[1,24]$} \\
\hline Cryptococcoid & $\begin{array}{l}\text { Vacuolated mononuclear cells with the presence of basophilic yeast-like bodies. } \\
\text { PAS stain fails to reveal fungal elements }\end{array}$ & {$[38,57-59]$} \\
\hline Eosinophilic $^{\mathrm{a}}$ & $\begin{array}{l}\text { Dense eosinophilic infiltrate into the dermis; must rule out eosinophilic derma- } \\
\text { tosis of hematologic malignancy }\end{array}$ & [32] \\
\hline Histiocytoid & $\begin{array}{l}\text { Dermal infiltrate of immature neutrophils that resemble histiocytes; IHC is posi- } \\
\text { tive for CD68 and MPO }\end{array}$ & {$[60,61]$} \\
\hline Lymphocytic $^{\mathrm{a}}$ & Exuberant dermal lymphocytic infiltrate & {$[30,31]$} \\
\hline Normolipemic xanthomized & $\begin{array}{l}\text { CD163-positive foam cells accompany dense neutrophilic infiltrate extending } \\
\text { into the deep dermis }\end{array}$ & [69] \\
\hline
\end{tabular}

$C D$ cluster of differentiation, $I H C$ immunohistochemistry, $I L$ interleukin, $i N O S$ inducible nitric oxide synthase, $M P O$ myeloperoxidase, $N D D H$ neutrophilic dermatosis of the dorsal hands, $P A S$ periodic acid Schiff, SS Sweet syndrome

${ }^{a}$ Since SS is classified based on the presence of dermal neutrophilic infiltration, we recommend against the use of SS as an umbrella term to describe entities that present histologically with eosinophilic or lymphocytic infiltrate, despite presenting clinically as SS

of extracutaneous SS is critical, as certain extracutaneous manifestations are reported to bear significant morbidity and mortality.

\subsubsection{Neuro-Sweet Disease}

SS has been reported to present with neurologic symptoms, most often meningitis and encephalitis. In 1999, Hisanaga et al. proposed the term 'neuro-Sweet disease' to describe a case of SS presenting with neurologic features [74]. Subsequently, in 2005, the investigators outlined a diagnostic criteria for neuro-Sweet disease that comprised four elements: (1) recurrent episodes of encephalitis and meningitis, with pronounced response to systemic corticosteroid therapy; (2) dermatologic features consistent with SS; (3) absence of cutaneous vasculitis, thrombosis, and typical uveitis; and (4) human leukocyte antigen (HLA) associations, with HLA-Cw1 or B54 positivity. A case of 'probable' neuroSweet disease would need to satisfy the first three elements outlined. A case meeting one of the features of criterion \#3 and either criterion \#2 or \#4 would be considered a case of 'possible' neuro-Sweet disease [74].

In 2019, Wallach et al. reviewed all reported cases of neuro-Sweet disease to describe the widening spectrum of this rare condition. In addition to the diagnostic neurological features of encephalitis and meningitis, a host of other neurological symptoms have been reported in neuro-Sweet disease: aphasia, ataxia, focal seizures, hemiparesis, hemisensory loss, and movement disorder. The authors also reported certain cases of neuro-Sweet disease to present with neurovascular accidents, including strokes and ophthalmic vein thrombosis. Imaging and cerebrospinal fluid analyses are highly variable across cases, and therefore of little diagnostic value [9].

Since the publication of the review by Wallach et al., five additional cases of neuro-Sweet disease have been added to the literature [75-79]. Of note, Hiraga et al. describe a patient who experienced recurrent neurologic episodes (consisting of meningoencephalitis, ocular flutter, and seizures) for 10 years prior to the development of skin lesions. This report emphasizes that the dermatologic manifestation of neuro-Sweet disease may remain latent for many years [75]. Neuro-Sweet disease may also present in conjunction with other disease states, and a case of neuro-Sweet disease occurring in the setting of Sjogren's syndrome has been recently reported [78]. 


\subsubsection{Ophthalmological Involvement}

Ocular involvement has been reported to occur in between 10 and $72 \%$ of SS patients [11,80-83], and usually presents as mild to moderate conjunctivitis that resolves with corticosteroid treatment [84]. However, ocular involvement may be more severe. Recently, cases of SS presenting with bilateral panuveitis $[85,86]$, central retinal artery occlusion [87], hemorrhagic conjunctivitis [88], meibomitis [89], and retinal detachment have been described [86]. In 2020, Mishra et al. reported a case of SS presenting with episcleritis that inexorably led to blindness despite treatment with systemic corticosteroids, intravitreal dexamethasone implant, systemic dapsone, and sub-Tenon triamcinolone [90].

\subsubsection{Pulmonary Involvement}

Involvement of lungs in SS is a rare phenomenon yet can be associated with significant morbidity and mortality. Manifestations of pulmonary involvement in SS include bronchiectasis [91], diffuse alveolar hemorrhage [92], ground glass opacities mimicking pneumonia [67, 91, 93, 94], obstructive lung disease [91], and pleural effusion [95]. Pulmonary involvement may follow skin involvement $[67,91,92,94$, 95] or the pulmonary manifestations may appear concurrently with dermatologic lesions [93]. Clinically, a patient with pulmonary involvement may present with pulmonary symptoms such as dyspnea [67, 91, 94, 95] or hemoptysis [92], or without any obvious pulmonary symptoms such that pulmonary involvement only becomes evident after analysis of imaging studies [93]. Bronchoalveolar lavage (BAL) will show a neutrophilic predominance, but a culture of BAL will be negative for organisms [91-93]. Pleural effusions, if present, may also be analyzed, although a recent case of SS presenting with a pleural effusion described the pleural effusion to be pauci-neutrophilic, being dominated instead by eosinophils and lymphocytes [95]. Thus, thoracocentesis of pleural effusions may not unequivocally clinch the diagnosis in favor of SS, although the procedure should still be performed to rule out malignancy and infection.

Recently, a case of SS with severe pulmonary involvement requiring lung transplant was described. In the allograft, SS recurred, presenting with diffuse bilateral airway thickening and sterile bronchopneumonia. Intravenous methyl prednisone led to regression of the pulmonary lesions, yet following a methyl prednisone taper, the lesions returned. Corticosteroid therapy was resumed and rilonacept was added, inducing disease remission [91]. Manglani et al. reported a similar case, where SS led to diffuse alveolar hemorrhage. Methyl prednisone therapy was initiated, yet the patient progressed to multiorgan dysfunction and expired [92]. While these cases are rare, they highlight the importance of maintaining SS on the differential when evaluating a patient with SS-like cutaneous lesions and sterile pneumonia.

\subsubsection{Other Sites}

Involvement of a variety of other extracutaneous sites has also been observed. Bilateral sensorineural hearing loss [96], laryngitis [97], myocarditis [98], and neutrophilic myositis leading to rhabdomyolysis [99] have been recently reported in literature. The gastrointestinal tract may also be involved, and may be accompanied by hepatic and/or renal involvement [2].

\subsection{Differential Diagnosis}

Although the diagnostic criteria for SS have been well established, the differential diagnosis is vast, and arriving at a final diagnosis is challenging. SS must be differentiated from certain panniculitides (e.g., erythema nodosum), vasculitides (e.g., polyarteritis nodosa), and infectious processes (e.g., chronic meningococcemia, erysipelas, infectious folliculitis) that also present as painful, erythematous nodules. SS may also present similarly to eosinophilic dermatoses and leukemia/lymphoma cutis. In 2019, Inamadar and Adya proposed an algorithm for approaching the patient with painful, erythematous nodules. They note chronicity, distribution (localized versus generalized), and configuration (centrifugal versus centripetal) to be key characteristics to consider, with SS typically presenting as acute onset, centripetal lesions in a generalized fashion [100]. Taken together with histological evidence of neutrophilic infiltrate and the characteristic constellation of inflammatory signs outlined by von den Driesch [29], such a rash is suggestive of SS.

In recent literature, SS has been reported to mimic cutaneous T-cell lymphoma [101], leprosy [102-104], leukemia cutis [105, 106], Mycobacterium haemophilum infection [107], RAS-associated autoimmune leukoproliferative disease, rheumatoid neutrophilic dermatoses [108], secondary syphilis [109], and synovitis acne pustulosis hyperostosis syndrome [110]. Conversely, SS has been reported to be mimicked by cutaneous metastasis [111] and rosacea-like dermatitis [63]. We summarize the possible differential diagnoses in Table 4.

Certain subtypes of SS in particular may be ostensibly inconspicuous from the infectious conditions they resemble. For instance, it is almost impossible to distinguish subcutaneous SS from cellulitis based upon clinical examination alone. Cellulitis-like SS, NDDH, and necrotizing SS too can be mistaken for an infectious process. NeuroSweet disease is indistinguishable from viral meningoencephalitis, and SS presenting with pulmonary involvement 
Table 4 Differential diagnosis of Sweet syndrome

\begin{tabular}{ll}
\hline Disease process & Conditions \\
\hline Infectious disease & Chronic meningococcemia \\
& Erysipelas \\
& Infectious folliculitis \\
& Leprosy \\
& Mycobacterium haemophilum \\
& Secondary syphilis \\
& Eosinophilic dermatosis \\
& RAS-associated autoimmune \\
Inflammatory conditions & leukoproliferative disease \\
& Rheumatoid neutrophilic derma- \\
& tosis \\
& Rosacea-like dermatitis \\
& Synovitis acne pustulosis hyperos- \\
& tosis syndrome \\
Cutaneous T cell lymphoma & Leukemia/lymphoma cutis \\
Neoplasm & Cutaneous metastasis \\
Eanniculitis & Erythema nodosum \\
Vasculitis & Cutaneous polyarteritis nodosa \\
& Nodular vasculitis \\
&
\end{tabular}

effectively masquerades as infectious pneumonia. As such, it is imperative to perform further confirmatory testing. $\mathrm{NDDH}$, necrotizing SS, and subcutaneous SS will all return negative bacterial cultures; lumbar puncture of a suspected case of neuro-Sweet disease will reveal sterile cerebrospinal fluid; and a BAL or thoracocentesis of a case of SS with pulmonary involvement will fail to show organisms. In these situations, a therapeutic trial of corticosteroids may be initiated, and if response is observed, then a diagnosis of SS may be supported.

\section{Revisiting Disease Associations}

\subsection{Sweet Syndrome in the Setting of Malignancy}

SS has been noted in the setting of a number of malignancies, and SS may precede, be concurrent with, or follow the diagnosis of malignancy. SS lesions may also precede a cancer's recurrence, thereby heralding it's return. A case of SS heralding the transformation of Fanconi's anemia to AML has been recently reported [19].

Hematologic malignancies in particular have been described in association with SS. The association of AML and SS has been the most studied. In a study of $2178 \mathrm{AML}$ patients, we have shown the incidence of SS to be $1 \%$. Additionally, we have further analyzed the patients with
AML who develop SS to show that $-5 / \operatorname{del}(5 q)$ karyotype and FMS-related tyrosine kinase-3 (FLT3) mutations are more prevalent among AML patients who develop SS than AML patients who do not develop SS [112]. A more recent study of 216 AML patients has shown the incidence of SS to be $5.5 \%$, although the study did not perform further molecular studies [113]. Several cases of SS arising in the setting of myelodysplastic syndrome (MDS) have also been described. In a retrospective study of 23 MDS patients with SS, two patients were diagnosed prior to, six concurrently with, and 15 after the diagnosis of SS [114]. Two cases of hairy cell leukemia presenting with SS [115, 116] and a case of myelofibrosis presenting with SS [117] have also been recently reported.

SS has also been recently associated with a number of solid organ malignancies including cervical cancer [118], cholangiocarcinoma [119], colorectal cancer [111], gastric adenocarcinoma [8], and lung cancer [8]. Thus, SS may be considered a rare cutaneous paraneoplastic syndrome associated with a host of malignancies.

\subsection{Sweet Syndrome and Infectious Triggers}

While SS itself is a non-infectious dermatosis, a number of infections have been reported to trigger or occur concurrently with SS. A 2020 Thai study of 88 patients with nontuberculous mycobacterial (NTM) infections reported the prevalence of SS to be $3.4 \%$, and concluded SS to be the most common reactive dermatosis in NTM infections [120]. The incidence of SS in other bacterial infections is less well characterized, although SS has been reported in the setting of infection with Burkholderia pseudomallei [121], Erysipelothrix rhusiopathiae [122], Mycobacterium tuberculosis [123], and Treponema pallidum [124, 125]. Viruses have also been reported in association with SS, with Hepatitis C [126], human immunodeficiency virus [127, 128], and severe acute respiratory syndrome coronavirus 2 (SARS-CoV-2) [129-131] being recently reported as culprits.

SS in the setting of fungal infections has also been described. In a Brazilian study of 342 patients with sporotrichosis, 10 patients were noted to develop SS [132]; coccidiomycosis [133] and histoplasmosis [134] have also been reported as fungal triggers. SS in the context of parasitic infections appears to be a less frequent occurrence, although SS in the setting of toxoplasmosis [135] and enterobiasis [136] has been reported.

Indeed, it is possible that that the occurrence of SS in the setting of infection be merely a coincidence. However, it is also possible that a bona fide association between SS and an infectious process exists. Mechanistically, it is plausible to suggest that an infection sets up a pro-inflammatory milieu that is propitious to the development of SS. We discuss 
possible mechanistic links in further depth in Section 8 of the manuscript.

\subsection{Other Disease Associations}

\subsubsection{Sweet Syndrome Associated with Autoimmune Diseases}

SS has been reported to occur in the setting of a variety of autoimmune conditions. Autoimmune connective tissue disorders in particular have been recently noted in association with SS and include Behçet's disease [68], mixed connective tissue disease [137], polymyalgia rheumatica [138], rheumatoid arthritis [139-141], Sjogren's syndrome [78, 142], and systemic lupus erythematous [143]. SS has also been reported in conjunction with eosinophilic granulomatosis with polyangiitis [144] and Hashimoto's thyroiditis [145]. Again, it is possible that co-existence of autoimmune conditions and SS is merely coincidental, and that there is no etiologic link between autoimmune disease and SS. However, as may be the case in SS occurring in the setting of infections, a dysregulated immune system in autoimmune states lends itself well to the development of SS.

\subsubsection{Sweet Syndrome in States of Immune Deficiency}

Somewhat paradoxically, SS has also been noted in a number of immunodeficiency states. In 2019, Cook et al. reported a case of SS occurring in a child with common variable immunodeficiency. They also reviewed the literature to summarize the cases of SS occurring in other immunodeficiency conditions, and noted SS to have been a finding in primary and secondary T-cell lymphopenia and chronic granulomatous disease [146].

In October 2021, Kiratikanon et al. reported 34 cases of SS occurring in the setting of adult-onset immunodeficiency (AOID), an immunodeficiency syndrome precipitated by anti-interferon gamma (IFN- $\gamma$ ) autoantibodies. The investigators reported that AOID increased the risk of developing SS, even after accounting for disseminated non-tuberculous mycobacterial infection as a possible confounder [147]. Indeed, it is difficult to reconcile this finding with our earlier hypothesis that a general state of immune over-activation contributes to SS pathogenesis, as SS has now been shown to occur in states of immunodeficiency in the absence of infectious agents. We attempt an explanation of this conundrum in Section 8 of the manuscript.

\subsubsection{Sweet Syndrome: An Extraintestinal Manifestation of Inflammatory Bowel Disease}

SS has been noted as an extraintestinal manifestation of inflammatory bowel disease (IBD) on numerous occasions; such an occurrence is not surprising, considering that PG is one of the most common cutaneous manifestations of both Crohn's disease and ulcerative colitis. In an Argentinian study of 444 IBD patients, the incidence of SS was observed to be $0.7 \%$, approximately half that of PG. In all cases of SS, corticosteroids induced complete lesion involution [148].

In 2021, Sleiman et al. conducted a systematic review of all patients with IBD who had associated SS. Based on their pooled analysis of 95 patients, they observed SS to follow the diagnosis of IBD $64.2 \%$ of the time, though SS was also noted to occur prior to and concurrently with the diagnosis of SS in 5.3\% and $29.5 \%$ of cases, respectively. Furthermore, SS was noted to occur both during an IBD flare as well as in periods of IBD quiescence. The investigators did not notice any clinical, histological, or laboratory differences between SS appearing in Crohn's disease versus SS appearing in ulcerative colitis. Corticosteroids were reported to be effective in $90.5 \%$ of cases [149].

\subsubsection{Other Associations}

SS has also been recently reported in association with amyloid nephropathy [150], hidradenitis suppurativa [41, 151], and sarcoidosis [152]. Possible pathogenic mechanisms between these conditions and SS remain to be established.

\section{An Updated List of latrogenic Causes}

Scores of drugs have been reported to trigger SS; granulocyte colony stimulating factor (G-CSF) and FLT3 inhibitors (a class of tyrosine kinase inhibitors that target AML with FLT3 mutations), have been reported as frequent iatrogenic triggers, although a variety of antimicrobial and antineoplastic agents have also been commonly implicated [2]. Several other medications have been recently added to the litany of iatrogenic triggers (Table 5). Of course, this list is not exhaustive, and only reflects novel drug associations reported in the last 3 years. One may refer to the review by Nelson et al. for a list of iatrogenic triggers reported prior to 2018 [2].

Given the impressive heterogeneity in the classes of drugs that have been implicated in instigating SS, it is unlikely that they contribute to SS pathogenesis in an identical manner. The mechanism of SS induction by G-CSF, FLT3 inhibitors, and all-trans retinoic acid (ATRA) is most amenable to explanation. As G-CSF mobilizes granulocytes from the bone marrow, it is possible that in some patients, G-CSF treatment causes an exuberant neutrophilic response. FLT3 inhibitors induce differentiation of myeloid blasts into mature neutrophils, which then localize to the dermis, yielding SS. Similarly, ATRA (a treatment for acute promyelocytic leukemia) causes differentiation of 
promyelocyte blasts; the mature cells can then migrate to the dermis, resulting in SS. SS seen with other drugs may occur as a reaction pattern. We discuss possible mechanistic links further in Section 8 of the manuscript, and also evaluate the quality of studies reporting these drug eruptions in Section 9.

\section{Therapeutic Options}

It is worth emphasizing that SS may resolve spontaneously; alternatively, SS may regress following the treatment of the underlying condition (e.g., malignancy) or following withdrawal of the putative offending drug. Thus, in instances of mild to moderate SS, reassurance, treatment of underlying malignancy, or discontinuation of the provoking medication may all be reasonable management options. However, if SS is more severe or if the patient desires treatment for cosmetic purposes, then pharmacotherapy may be initiated [153].

Corticosteroids constitute the mainstay of SS treatment, with most cases of SS being exquisitely responsive to prednisone at a dosage of $0.5-1 \mathrm{mg} / \mathrm{kg} / \mathrm{day}[7,10]$. In a retrospective study of 83 SS patients, of whom 44 were treated with systemic corticosteroids, all patients responded to treatment [7]. A $100 \%$ response rate was also observed in another retrospective study of 24 SS patients who were managed with systemic corticosteroids [6]. However, in certain instances, SS may be refractory to steroid treatment, or steroid-sparing therapy may be desired. In 2019, Lee et al. reported a case of SS recalcitrant to 2 years of steroid treatment. Due to the long-term use of corticosteroids, the patient developed severe hypertrophic scars on the buttocks and lower extremities [66]. Recently, an SS patient undergoing prednisone treatment was reported to develop infection with coronavirus disease 19 (COVID-19) and subsequently die from respiratory failure. While the extent to which steroid treatment contributed to the patient's eventual death is unclear (of note, the patient also had Fanconi's anemia), patients taking high-dose corticosteroids have been deemed vulnerable to COVID-19 [154]. In these situations, alternatives to corticosteroids may be sought.

Of all steroid-sparing therapies, indomethacin is supported by the highest level of evidence. In an 18-patient prospective trial, indomethacin was administered at a dosage of $150 \mathrm{mg} /$ day for the first week and $100 \mathrm{mg} /$ day for 2 weeks thereafter. Ninety-four percent of patients responded to treatment and did not experience relapse [155]. While compelling, the study should be replicated in a larger cohort to be further validated. Colchicine also appears to be efficacious. In a 20-patient retrospective study, $1-1.5 \mathrm{mg} / \mathrm{day}$ of colchicine for a mean duration of 15 days led to remission in all but two patients; none of the responders endorsed lesion recurrence [156]. Smaller case series of $<10$ patients
Table 5 Recently reported iatrogenic causes of Sweet syndrome. For a list of previously reported associations, refer to Nelson et al. [2] and Heath and Ortega-Loayaza [166]

\begin{tabular}{ll}
\hline Drug & References \\
\hline Clopidogrel & {$[174]$} \\
Dapagliflozin & {$[175]$} \\
Enasedinib & {$[176]$} \\
Hydroxychloroquine & {$[142]$} \\
Ixazomib & {$[177-179]$} \\
Lamotrigine & {$[180]$} \\
Letrozole & {$[181]$} \\
LMWH & {$[182]$} \\
Midostaurin & {$[183]$} \\
Palbociclib & {$[184]$} \\
Pemetrexed & {$[185]$} \\
Ruxolitinib & {$[186]$} \\
SARS-CoV-2 vaccination & {$[187-191]$} \\
Tocilizumab & {$[138]$} \\
\hline
\end{tabular}

$L M W H$ low molecular weight heparin, SARS-CoV-2 severe acute respiratory syndrome coronavirus 2

have also shown efficacy for clofazimine [29] and potassium iodide $[157,158]$. Isolated case reports have also shown efficacy for azathioprine, cyclophosphamide, cyclosporine, etretinate, IFN- $\alpha$, rituximab, tacrolimus, and tetracyclines, and have been reviewed by Nelson et al. [2].

More recent studies have described additional therapeutic options for SS. In a 20-patient retrospective study, acitretin at a dosage of $10-50 \mathrm{mg} /$ day contributed to complete/near complete remission of SS in all patients; moreover, 14 patients experienced remission within 2 weeks of initiating treatment [159]. Dapsone is also supported by a modicum of evidence. In an 11-patient retrospective study, Hrin et al. described dapsone, at a median daily dosage of $100 \mathrm{mg}$ for a median duration of 13 months, to result in an $82 \%$ response rate. However, two patients experienced myelosuppression, warranting treatment cessation [160].

Recent case reports have also demonstrated efficacy for baricitinib (a Janus kinase inhibitor) [141], thalidomide [128], and combination acitretin and colchicine therapy [161]. A number of biologic agents have also been recently reported as viable management options for refractory SS: adalimumab [162] and infliximab [23, 37, 163] (anti-tumor necrosis factor alpha [TNF $\alpha]$ agents), anakinra [164] and rilonacept [91] (anti-IL1 agents), and tocilizumab (antiIL6) $[146,150]$. Ustekinumab, an IL12 and IL23 inhibitor, was reported to be ineffective in a case of recalcitrant SS [165].

We summarize the recently reported therapeutic options in Table 6 and include indomethacin and colchicine as they arise to 'B' and 'C' levels of evidence, respectively. Given 
the paucity of evidence-based therapies as well as the various co-morbidities afflicting SS patients, it is difficult to provide universal treatment guidelines. While corticosteroids should remain first-line therapies, second-line agents should be personalized based on patient comorbidities, past medical history, and preference.

\section{Established and Emerging Paradigms of SS Pathogenesis}

In 2019, Heath and Ortega-Loayza reviewed the proposed mechanisms of SS pathogenesis, and noted the pathogenesis of SS to be likely multifactorial [166]. Here, we emphasize new developments in SS pathogenesis.

\subsection{Overexuberant Neutrophil Proliferation, Maturation, and Dermal Honing}

Heath and Ortega-Loayaza noted aberrancy in neutrophilic proliferation, maturation, and dermal localization to be one possible paradigm to conceptualize SS pathogenesis. Development of SS under ATRA, G-CSF, and FLT3 inhibitor treatment supports this theory [166].

Additionally, the successful management of SS with acitretin [159] further supports this conjecture, as acitretin has been shown to inhibit neutrophil migration [167]. A similar hypothesis posits that in cases of hematologic malignancy, dysplastic neutrophils (of the same clonal origin as malignant myeloblasts) have an inherently greater capacity to localize to the dermis and incite inflammation [166]. This hypothesis is supported by a 2020 study that showed that the malignant myeloid clone and the skin-infiltrating neutrophils in SS share a common clonal progenitor. However, the mutation profile observed was distinct across patients, suggesting that particular genetic mutations may not predict propensity for dermal invasion. Additionally, as this study was limited to only ten patients, further studies are needed to validate these findings [168].

\subsection{Genetic Predisposition}

Genetics have also been proposed to increase susceptibility to SS, and such a hypothesis is supported by increased prevalence of HLA-Cw1 or B54 in patients with neuroSweet disease [74]. An association between SS and familial Mediterranean fever (which results from pathogenic variants in the MEFV gene that codes for pyrin, an intracellular pattern recognition receptor) also supports a genetic basis for SS [166].

\subsection{Cytokine and T-Cell Dysregulation}

Cytokines also likely contribute to SS. As reviewed by Heath and Ortega-Loayaza, a Th1 predominant response has been observed in SS. Recent reports of SS responding to the TNF $\alpha$ inhibitors adalimumab [162] and infliximab [23, 37, 163], and the IL-1 inhibitors anakinra [164] and rilonacept [91], support a Th1 axis bias.

However, more recent literature suggests that the pathogenesis of SS may be more nuanced than just Th1 axis dysregulation. In fact, a recent case report of SS failed to reveal Th1 predominance; instead, the cytokine signature was more diverse, showing elevation of IL6 [77], a cytokine that simultaneously inhibits the Th1 axis while evoking a Th2 response [169]. Indeed, the recent reports of refractory SS being managed with tocilizumab, an IL6 receptor antagonist, further support the notion that IL6 is over-expressed in SS [146, 150].

The paradoxical induction of SS by adalimumab [41] also emphasizes that the inflammation in SS may not be limited to Th1 axis dysregulation. The occurrence of SS in AOID further highlights this complexity [147]. As IFN- $\gamma$ is a major Th1 cytokine, the emergence of SS in spite of an IFN- $\gamma$ blockade (that is naturally present in AOID) suggests that either TNF $\alpha$ and IL- $1 \beta$ are able to compensate for the loss of IFN- $\gamma$, or that inflammation is mediated by a different $\mathrm{T}$-cell axis altogether.

Perhaps, in certain cases of SS, the inflammatory response is dominated by the Th17 axis. Indeed, this

Table 6 Recently reported treatments for Sweet syndrome and their corresponding level of evidence

\begin{tabular}{lll}
\hline Treatment & Level of evidence & References \\
\hline Acitretin & $\mathrm{C}$ & {$[159]$} \\
Acitretin + colchicine & $\mathrm{D}$ & {$[161]$} \\
Baricitinib & $\mathrm{D}$ & {$[141]$} \\
Biologic agents & & \\
Adalimumab & $\mathrm{D}$ & {$[162]$} \\
Anakinra & $\mathrm{D}$ & {$[164]$} \\
Infliximab & $\mathrm{D}$ & {$[23,37,192]$} \\
Rilonacept & $\mathrm{D}$ & {$[91]$} \\
Tocilizumab & $\mathrm{D}$ & {$[146,150]$} \\
Colchicine & $\mathrm{C}$ & {$[156]$} \\
Clofazimine & $\mathrm{D}$ & {$[29]$} \\
Corticosteroids & $\mathrm{C}$ & {$[6-8]$} \\
Dapsone & $\mathrm{C}$ & {$[160]$} \\
Indomethacin & $\mathrm{B}$ & {$[155]$} \\
Potassium iodide & $\mathrm{D}$ & {$[157,158]$} \\
Thalidomide & $\mathrm{D}$ & {$[128]$} \\
\hline
\end{tabular}

$B$ lesser quality randomized controlled trial or prospective study, $C$ case-control study or retrospective study, $D$ case series or case reports 
would explain the occurrence of SS in AOID as well as the induction of SS by adalimumab. With an inhibited Th1 axis, the Th17 axis may be upregulated in a manner that is over-compensatory, resulting in immune dysregulation that may manifest as SS. Such a hypothesis has been advanced by investigations of autoimmunity in mice [170]; however, this hypothesis is undermined by the recent case report of SS refractory to ustekinumab [165].

Another possibility, albeit speculative, is that some cases of SS are marked by Th2 axis dysregulation. Indeed, such a hypothesis would be consistent with the case report of SS associated with the parasite Enterobius vermicularis, which would naturally induce $\operatorname{Th} 2$ pathway activation [136].

\subsection{Pathergy and Photoinduction}

Certain cases of SS have also been attributed to Koebner's phenomenon [55, 171, 172]. In such cases, it is possible that trauma to the epithelium generates an inflammatory response that favors SS induction. Indeed, due to the risk of possible exacerbation of SS due to intralesional therapies or injections, it may be advisable to use oral therapies for SS first before resorting to injectable medications. Cases of photoinduced SS have also been described. Once again, the pathogenesis of this entity remains to be elucidated, although some have proposed that ultraviolet light stimulates keratinocytes to produce IL-8 and TNF $\alpha$, which in turn recruit neutrophils to the dermis [65].

\subsection{A Unified Paradigm of Pathogenesis: An Unlikely Possibility?}

Altogether, it is likely that the various mechanisms contributing to SS cannot be distilled into an elegant, unified scheme. Each individual with SS is likely to be slightly different, with unique external chemical and physical insults, immune dysregulation (due to autoimmunity or malignancy), and/or predisposing genetics. Additionally, with emerging literature, our understanding of SS will continue to evolve. For instance, an April 2021 study of 37 SS patients found neutrophil extracellular traps (NETs; net-like proteins that immobilize pathogens) to be expressed in the tissue of $37.8 \%$ of patients [173]; these neutrophil extracellular traps may in turn stimulate macrophages for cytokine production. Additionally, the study investigators noted partial colocalization of NETs with TNF $\alpha$ and IL- $1 \beta$, suggesting that the cytokine dysregulation and NETs may synergistically contribute to SS. While targeting NETs may not be of therapeutic potential, they nonetheless comprise another piece of the SS pathogenesis puzzle.
Moreover, many questions in SS pathogenesis remain to be answered. Are the mechanisms of SS pathogenesis conserved between the different variants of SS or are they the same? Is there over-regulation of the Janus kinase signal transducer and activator of transcription (JAK-STAT) pathway in SS? The successful treatment of SS with baricitinib, a JAK inhibitor, seems to suggest so [141], yet this hypothesis remains to be confirmed by tissue analysis.

\section{Study Quality Assessment}

Among the 30 cases of iatrogenic SS that we reviewed using the Naranjo Drug Reaction Probability Scale [3], 24 studies earned a score between 1 and 4 and thus represent 'possible' ADRs; six studies earned a score between 5 and 8 and thus represent 'probable' ADRs; and no study earned a score $\geq 9$, the threshold for an ADR to be considered 'definite'. Among the 15 treatment-oriented studies we reviewed using the Tool for evaluating the methodological quality of case reports and case series [4], one study was graded a score of 3 , four studies a score of 4 , nine studies a score of 5 , and one study a score of 6 , out of a best possible score of 8 points.

\section{Review Limitations}

We acknowledge our review to be subject to important limitations. Selection bias is one limitation of our review, as we only included studies published in the English language. Furthermore, the quality of the studies we reviewed limits the strength of our findings: $80 \%$ of the drug-induced cases of SS reported can only be considered 'possible' ADRs; additionally, of the treatment-focused studies we reviewed, none earned a score of 7 or 8 , and $93 \%$ had scores $\leq 5 / 8$.

More specifically, none of the treatment-focused studies we reviewed excluded spontaneous remission. Indeed, spontaneous remission of SS has been reported in the literature [153]; thus, the possibility of spontaneous remission confounds the therapeutic potential of the treatments we review. Furthermore, none of the treatment-focused studies reported a challenge/re-challenge phenomenon; altogether then, the treatment-focused studies were weakest in the 'causality' domain defined by Murad and colleagues, suggesting that while there may be a temporal association between initiation of treatment and disappearance of SS, the causal link is tenuous.

The same can be said of the articles reporting druginduced SS. As SS can also arise spontaneously in the absence of any offending medications, it is possible that the association of SS with certain drugs is spurious. Publication bias compounds this issue, as there is greater novelty in reporting cases of iatrogenic rather than idiopathic SS. 


\section{Conclusions}

Since Dr Sweet's 1964 report, our understanding of SS has expanded considerably. SS is now recognized to present along a broad spectrum that encapsulates not just "raised painful plaques," but also other clinical variants: bullous SS, cellulitis-like SS, necrotizing SS, and neutrophilic dermatoses of the dorsal hands. A wider histological spectrum has also been recognized, and though "dense dermal infiltration with mature neutrophil polymorphs" remains the prototypic histological descriptor, cryptococcoid, histiocytoid, and subcutaneous variants have been added to the literature. SS has also been reported to present with extracutaneous manifestations that involve virtually every organ system. Neurological (neuro-Sweet disease), ophthalmological, and pulmonary involvement may be clinically the most dramatic. The differential diagnosis for SS is vast. To that end, establishing concordance between clinical, histological, and laboratory findings is crucial prior to rendering a diagnosis of SS.

SS has been reported in a variety of malignancies and infectious processes. SS likely represents a bona fide extracutaneous manifestation of IBD. SS has also been reported in conjunction with a host of autoimmune states and, somewhat paradoxically, in states of immunodeficiency; it is unclear, however, whether these associations are due to a shared etiology or are just coincidental occurrences. A number of drugs have also been reported to trigger SS. ATRA, FLTR3 inhibitors, and G-CSF most likely represent true iatrogenic triggers. Other drugs may induce SS through a hypersensitivity mechanism, or the appearance of SS following the initiation of a particular drug may simply be spurious.

With regards to therapy, there is a paucity of highquality, treatment-focused studies. Nevertheless, given the brisk response to corticosteroids that is observed in most SS patients, corticosteroids are considered to be first-line therapies. Treatment with indomethacin is supported by the highest level of evidence, and may be attempted if SS does not respond to steroid therapy. Acitretin, colchicine, and dapsone are supported by retrospective studies. Isolated case reports have also shown efficacy for biologic agents. Ultimately, treatment should be personalized based upon patient co-morbidities, past medical history, and preference.

A canonical dogma to conceptualize SS pathogenesis likely does not exist. Rather, SS pathogenesis appears to be multifactorial, a product of external chemical and physical insults, host immune dysregulation (due to autoimmunity or malignancy), and/or predisposing genetic elements.

Our knowledge of SS pathogenesis, disease associations, and treatment options is incomplete and evolving. Tissue analysis may afford us an opportunity to better characterize the molecular milieu of SS. Prospective or randomized controlled studies should also be conducted to establish evidence-based therapies for SS, and, large, multi-center, case-control studies may offer more robust evidence for potential disease associations.

Supplementary Information The online version contains supplementary material available at https://doi.org/10.1007/s40257-022-00673-4.

\section{Declarations}

Funding John R Stanton Fellowship; Blanche Bender Professorship for Cancer Research; MD Anderson Core Grant P30 CA16672.

Conflict of interest Authors declare no conflicts of interest.

Availability of data and material Articles used in this review are available in the public domain.

Code availability Not applicable.

Ethics approval Not applicable.

Consent to participate Not applicable.

Consent to publish Not applicable.

Author contributions TPJ conceived the idea for this review, performed the literature search, and drafted the manuscript. TPJ, SKF, and DAH evaluated study quality. MD provided expert guidance and critically revised the work. All authors read and approved the final submitted version.

\section{References}

1. Sweet RD. An acute neutrophilic dermatosis. Br J Dermatol. 1964;76:349-56.

2. Nelson CA, Stephen S, Ashchyan HJ, James WD, Micheletti RG, Rosenbach M. Neutrophilic dermatoses: Pathogenesis, Sweet syndrome, neutrophilic eccrine hidradenitis, and Behçet disease. J Am Acad Dermatol. 2018;79:987-1006.

3. Naranjo CA, Busto U, Sellers EM, Sandor P, Ruiz I, Roberts EA, et al. A method for estimating the probability of adverse drug reactions. Clin Pharmacol Ther. 1981;30:239-45.

4. Murad MH, Sultan S, Haffar S, Bazerbachi F. Methodological quality and synthesis of case series and case reports. BMJ Evid Based Med. 2018;23:60-3.

5. Cohen PR, Kurzrock R. Sweet's syndrome and cancer. Clin Dermatol. 1993;11:149-57.

6. Zheng S, Li S, Tang S, Pan Y, Ding Y, Qiao J, et al. Insights into the characteristics of sweet syndrome in patients with and without hematologic malignancy. Front Med (Lausanne). 2020;7:20.

7. Nelson CA, Noe MH, McMahon CM, Gowda A, Wu B, Ashchyan $\mathrm{HJ}$, et al. Sweet syndrome in patients with and without malignancy: a retrospective analysis of 83 patients from a tertiary academic referral center. J Am Acad Dermatol. 2018;78:303309.e4.

8. Dan H, Yanmei L, Yue X, Xian J. Sweet syndrome associated with malignancies: a retrospective analysis of 25 patients from West China hospital. Dermatol Ther. 2020;33:e13588. 
9. Wallach AI, Magro CM, Franks AG, Shapiro L, Kister I. Protean neurologic manifestations of two rare dermatologic disorders: sweet disease and localized craniofacial scleroderma. Curr Neurol Neurosci Rep. 2019;19:11.

10. Amouri M, Masmoudi A, Ammar M, Boudaya S, Khabir A, Boudawara T, et al. Sweet's syndrome: a retrospective study of 90 cases from a tertiary care center. Int J Dermatol. 2016;55:1033-9.

11. Rochet NM, Chavan RN, Cappel MA, Wada DA, Gibson LE. Sweet syndrome: clinical presentation, associations, and response to treatment in 77 patients. J Am Acad Dermatol. 2013;69:557-64.

12. Halpern J, Salim A. Pediatric sweet syndrome: case report and literature review. Pediatr Dermatol. 2009;26:452-7.

13. Jagati A, Shrivastava S, Baghela B, Agarwal P, Saikia S. Acquired cutis laxa secondary to Sweet syndrome in a child (Marshall syndrome): a rare case report. J Cutan Pathol. 2020;47:146-9.

14. Stepien AL, Perniciaro C, Kwong P, Rosario-Collazo J, Krishnamurthy K. Infantile histiocytoid Sweet syndrome without an underlying systemic association. JAAD Case Rep. 2021;17:96-9.

15. Aghababaie A, Patey R. A case of likely acute febrile neutrophilic dermatosis in a 17-year-old male presenting to general paediatrics. BMJ Case Rep. 2020;13:e233309.

16. Wat J, Wat M, Honda K. Vesiculobullous eruption in neutropenic patient with Crohn's disease. JAAD Case Rep. 2020;6:178-80.

17. Miranda E, Meza R, Kolbach M, Torres J, Harris PR. Sweet syndrome in pediatric active ulcerative colitis. Am J Gastroenterol. 2021;116:234.

18. AlRayes J, Al-Sabah H, Fekry A, Nanda A. Progressive erythematous papules and plaques in an infant. Clin Exp Dermatol. 2020;45:235-7.

19. Webber L, Cummins M, Mann R, Shaw L, Ghinai R, Mahon C. Panniculitis in a 3-year-old child with Fanconi anemia-associated bone marrow hypoplasia heralds transformation to acute myeloid leukemia. Pediatr Dermatol. 2019;36:725-7.

20. Zhou AE, Weddington CM, Ge S, Hoegler KM, Driscoll MS. Pediatric sweet syndrome. Clin Case Rep. 2021;9:e04762.

21. Bucchia M, Barbarot S, Reumaux H, Piram M, Mahe E, Mallet S, et al. Age-specific characteristics of neutrophilic dermatoses and neutrophilic diseases in children. J Eur Acad Dermatol Venereol. 2019;33:2179-87.

22. Turner M, Chauhan K. Subcutaneous sweet syndrome presenting as cellulitis in a pregnant female. Cureus. 2021;13:e17999.

23. Smolovic BD, Gajic-Veljic MD, Nikolic MM, Muhovic DF. Pregnancy-induced sweet's syndrome treated with infliximab. Med Princ Pract. 2019;28:196-8.

24. Stalder R, Brembilla N, Conrad C, Yawalkar N, Navarini A, Boehncke WH, et al. IL-17E, iNOS and Arginase1 as new biomarkers in the identification of neutrophilic dermatoses. Clin Exp Dermatol. 2021. https://doi.org/10.1111/ced.14988.

25. Lim J-H, Sim W-Y, Lew B-L. Sweet's syndrome limited on the palms and soles: a case report. Ann Dermatol. 2021;33:459-62.

26. Ensley D, Evans GH. Genital sweet's syndrome in a patient with acute myelogenous leukemia. Urol Case Rep. 2020;32:101235.

27. Errichetti E, Stinco G. Dermatoscopy in life-threatening and severe acute rashes. Clin Dermatol. 2020;38:113-21.

28. Su WP, Liu HN. Diagnostic criteria for Sweet's syndrome. Cutis. 1986;37:167-74.

29. von den Driesch P. Sweet's syndrome (acute febrile neutrophilic dermatosis). J Am Acad Dermatol. 1994;31:535-56 (quiz 557-560)

30. Peteln I, Dolenc-Voljč M, Jurčić V. Neutrophilic dermatosis of the dorsal hands (acral Sweet syndrome) with predominantly lymphocytic dermal infiltrate. J Cutan Pathol. 2020;47:104-7.
31. Panigrahi A, Biswas SK, Sil A, Bhanja DB. Neutrophilic dermatosis of the hands with palmar involvement and predominant lymphomononuclear cell infiltration. Indian J Dermatol. 2021;66:191-4.

32. Borda LJ, Kallis PJ, Pavlis J, Alqatari M, Romanelli P, Yosipovitch G. Sweet syndrome with marked eosinophilic infiltrate. Cutis. 2020;105:E4-6.

33. Walker DC, Cohen PR. Trimethoprim-sulfamethoxazole-associated acute febrile neutrophilic dermatosis: case report and review of drug-induced Sweet's syndrome. J Am Acad Dermatol. 1996;34:918-23.

34. Chen O, Partarrieu-Mejías F, Alarcón-Cabrera R. Erythema and bullae on the face and hands of a farm worker. Clin Exp Dermatol. 2019;44:99-101.

35. Giannoni M, Rizzetto G, Sapigni C, Paolinelli M, Tagliati C, Diotallevi F, et al. Bullous Sweet's syndrome in a patient with ulcerative colitis: a rare case report. Acta Dermatovenerol Alp Pannonica Adriat. 2020;29:153-5.

36. Esposito I, Fossati B, Peris K, De Simone C. A rare case of bullous Sweet's syndrome in a patient with inactive ulcerative colitis. J Eur Acad Dermatol Venereol. 2019;33:e380-1.

37. Knöpfel N, Theiler M, Luchsinger I, Hafner B, Brunner C, Kolm I, Weibel L. Infliximab for the treatment of recalcitrant bullous Sweet syndrome in a 10-year-old girl. Pediatr Dermatol. 2020;37(6):1183-4.

38. Sherban A, Fuller C, Sethi M, McGeehin E, Hirokawa D, Guerrieri $\mathrm{C}$, et al. Bullous hemorrhagic Sweet syndrome with cryptococcoid neutrophils in patients positive for antineutrophil cytoplasmic antibody without primary vasculitis. JAAD Case Rep. 2020;6:1196-200.

39. Mitaka H, Jammal R, Saabiye J, Yancovitz S, Perlman DC. Giant cellulitis-like Sweet syndrome: an underrecognized clinical variant mimicking skin and soft tissue infection. IDCases. 2020;21:e00874.

40. Okuyama S, Nito T, Yanagawa N, Tajima K. Giant cellulitislike Sweet syndrome as an initial clinical presentation of acute myeloblastic leukemia with $\mathrm{t}(6 ; 9)(\mathrm{p} 23 ; \mathrm{q} 34)$ : DEK-CAN and internal duplications of FMS-like tyrosine kinase 3. Ann Hematol. 2019;98:787-8.

41. Canal Garcia E, Vargas Ramos JDP, Aguayo OR. Cellulitis-like Sweet syndrome caused by adalimumab therapy for severe hidradenitis suppurativa. Australas J Dermatol. 2020;61:e448-9.

42. Kroshinsky D, Alloo A, Rothschild B, Cummins J, Tan J, Montecino R, et al. Necrotizing Sweet syndrome: a new variant of neutrophilic dermatosis mimicking necrotizing fasciitis. J Am Acad Dermatol. 2012;67:945-54.

43. Sanchez IM, Lowenstein S, Johnson KA, Babik J, Haag C, Keller JJ, et al. Clinical features of neutrophilic dermatosis variants resembling necrotizing fasciitis. JAMA Dermatol. 2019;155:79-84.

44. Paul S, Jammal N, Akhave N, Aung PP, Loghavi S, Jain N, et al. Atypical cases of necrotizing sweet syndrome in patients with myelodysplastic syndrome and acute myeloid leukaemia. Br J Haematol. 2020;191:e10-3.

45. Anand A, Gentile T, Kato H, Wang Q. Recurrent soft tissue inflammation, necrotizing fascitis or Sweet syndrome, diagnostic dilemma. Clin Case Rep. 2019;7:2483-7.

46. Gowda A, Christensen L, Polly S, Barlev D. Necrotizing neutrophilic dermatosis: a diagnostic challenge with a need for multidisciplinary recognition, a case report. Ann Med Surg (Lond). 2020;57:299-302.

47. Miyagami T, Suyama Y, Takahashi Y, Yang K-S, Naito T. Man with thigh pain. Ann Emerg Med. 2020;75:305-8. 
48. Husted A, Udholm S, Udholm N. Necrotising Sweet's syndrome: a rare presentation of Sweet's syndrome with unilateral painful swelling of the neck. BMJ Case Rep. 2021;14:e244179.

49. Strutton G, Weedon D, Robertson I. Pustular vasculitis of the hands. J Am Acad Dermatol. 1995;32:192-8.

50. Galaria NA, Junkins-Hopkins JM, Kligman D, James WD. Neutrophilic dermatosis of the dorsal hands: pustular vasculitis revisited. J Am Acad Dermatol. 2000;43:870-4.

51. Micallef D, Bonnici M, Pisani D, Boffa MJ. Neutrophilic dermatosis of the dorsal hands: a review of 123 cases. J Am Acad Dermatol. 2019;S0190-9622(19):32678-87.

52. Arandes-Marcocci J, Altemir-Vidal A, Iglesias-Plaza A, Fernández-Figueras MT, Salleras-Redonnet M. Neutrophilic dermatosis of the hands with palmar involvement: does it have clinical implication? Int J Dermatol. 2020;59:736-8.

53. Mobini N, Sadrolashrafi K, Michaels S. Neutrophilic dermatosis of the dorsal hands: report of a case and review of the literature. Case Rep Dermatol Med. 2019;2019:8301585.

54. Phillips D, Cohen SN, Muttoni EMU, Low SE, Ngan K. Necrotic ulceration of the hand case review: think beyond infection. $\mathrm{J}$ Emerg Nurs. 2021;47:379-83.

55. Gloor AD, Feldmeyer L, Borradori L. Neutrophilic dermatosis of the dorsal hands triggered by mechanical trauma. J Eur Acad Dermatol Venereol. 2021;35:e20-1.

56. Rodríguez-Villa Lario A, Piteiro-Bermejo AB, Vélez Velázquez D. Generalised pustulous Sweet's syndrome. Rev Clin Esp (Barc). 2021;S2254-8874(21)00103-X. https://doi.org/10.1016/j. rceng.2019.11.019.

57. Ko JS, Fernandez AP, Anderson KA, Burdick LM, Billings SD, Procop GW, et al. Morphologic mimickers of Cryptococcus occurring within inflammatory infiltrates in the setting of neutrophilic dermatitis: a series of three cases highlighting clinical dilemmas associated with a novel histopathologic pitfall. J Cutan Pathol. 2013;40:38-45.

58. Wilson J, Gleghorn K, Kelly B. Cryptococcoid Sweet's syndrome: two reports of Sweet's syndrome mimicking cutaneous cryptococcosis. J Cutan Pathol. 2017;44:413-9.

59. Mazzei ME, Guerra A, Dufrechou L, Vola M. Cryptococcoid Sweet syndrome: a clinical and histologic imitator of cryptococcosis. Actas Dermosifiliogr (Engl Ed). 2021;112:79-80.

60. Requena L, Kutzner H, Palmedo G, Pascual M, Fernández-Herrera J, Fraga J, et al. Histiocytoid Sweet syndrome: a dermal infiltration of immature neutrophilic granulocytes. Arch Dermatol. 2005;141:834-42.

61. Haber R, Feghali J, El Gemayel M. Risk of malignancy in histiocytoid Sweet syndrome: a systematic review and reappraisal. J Am Acad Dermatol. 2020;83:661-3.

62. Alegría-Landa V, Rodríguez-Pinilla SM, Santos-Briz A, Rodríguez-Peralto JL, Alegre V, Cerroni L, et al. Clinicopathologic, immunohistochemical, and molecular features of histiocytoid Sweet syndrome. JAMA Dermatol. 2017;153:651-9.

63. Kiyohara T, Shimada S, Ohnishi S, Miyamoto M, Shijimaya T, Nagano N, et al. Idiopathic histiocytoid Sweet syndrome with a butterfly rash-like appearance: a confusing case histologically mimicking rosacea-like dermatitis. J Dermatol. 2020;47:e14-5.

64. Wark KJ, Crawshaw H. Histiocytoid Sweet syndrome. Med J Aust. 2019;211:400-400.e1.

65. Sano Y, Moriki M, Yagi H, Tokura Y. Photoinduced histiocytoid Sweet's syndrome. J Dermatol. 2019;46:e378-80.

66. Lee KP, Tschen JA, Koshelev MV. Histiocytoid Sweet syndrome recalcitrant to prednisone causing severe scarring. JAAD Case Rep. 2019;5:937-9.

67. Miura T, Misa K, Yamamoto T. Subcutaneous Sweet syndrome mimicking cellulitis in a patient with myelodysplastic syndrome and subsequent secondary pulmonary alveolar proteinosis. Clin Exp Dermatol. 2020;45:763-4.
68. Vargas-Mora P, Valenzuela F, Kaplan V, Carreño L. Subcutaneous Sweet's syndrome associated with the onset of Behcet's disease. An Bras Dermatol. 2021;96:644-5.

69. Kamimura A, Yanagisawa H, Tsunemi Y, Kusano T, Arai E, Tsuchida T, et al. Normolipemic xanthomatized Sweet's syndrome: A variant of Sweet's syndrome with myelodysplastic syndrome. J Dermatol. 2021;48:695-8.

70. So JK, Carlos CA, Frucht CS, Cohen PR. Histiocytoid giant cellulitis-like Sweet's syndrome: case report and review of the literature. Dermatol Online J. 2015;21:13030/qt0682f5wp.

71. Pătraşcu V, Geoloaica LG, Ciurea RN. Recurrent idiopathic Sweet syndrome - case report and literature review. Curr Health Sci J. 2020;46:90-8.

72. Burke N, Saikaly SK, Motaparthi K, Bender NR. Malignancyassociated Sweet syndrome presenting with simultaneous histopathologic and morphologic variants. JAAD Case Rep. 2021;14:104-7.

73. Wallach D, Vignon-Pennamen M-D. Pyoderma gangrenosum and Sweet syndrome: the prototypic neutrophilic dermatoses. Br J Dermatol. 2018;178:595-602.

74. Hisanaga K, Hosokawa M, Sato N, Mochizuki H, Itoyama Y, Iwasaki Y. "Neuro-sweet disease": benign recurrent encephalitis with neutrophilic dermatosis. Arch Neurol. 1999;56:1010-3.

75. Hiraga A, Ozaki D, Oikawa M, Araki N, Kuwabara S. Recurrent neurological episodes for 10 years preceding skin lesions in neuro-sweet disease. Intern Med. 2019;58:3469-72.

76. Mitamura K, Yamamoto Y, Norikane T, Takata T, Nishiyama Y. Evaluation of the therapeutic response by $11 \mathrm{C}$-methionine PET in a case of neuro-sweet disease. Clin Nucl Med. 2020;45:962-4.

77. Kusaka H, Nagatani K, Sato T, Minota S. Increase of a wide range of bioactive substances in an active phase of neuro-Sweet disease. BMJ Case Rep. 2020;13:e233457.

78. Kodama T, Yamazaki Y, Takeo H. Neuro-Sweet disease in a Japanese woman with Sjögren's syndrome. BMJ Case Rep. 2019;12:e232933.

79. Hoffmann E, Boßelmann C, Forchhammer S, Lerche H, Freilinger T. Neuro-Sweet syndrome-a rare differential diagnosis in aseptic meningoencephalitis. Neurol Res Pract. 2019;1:36.

80. Cohen PR, Talpaz M, Kurzrock R. Malignancy-associated Sweet's syndrome: review of the world literature. J Clin Oncol. 1988;6:1887-97.

81. Kemmett D, Hunter JA. Sweet's syndrome: a clinicopathologic review of twenty-nine cases. J Am Acad Dermatol. 1990;23:503-7.

82. Sitjas D, Puig L, Cuatrecasas M, De Moragas JM. Acute febrile neutrophilic dermatosis (Sweet's syndrome). Int J Dermatol. 1993;32:261-8.

83. Gunawardena DA, Gunawardena KA, Ratnayaka RM, Vasanthanathan NS. The clinical spectrum of Sweet's syndrome (acute febrile neutrophilic dermatosis) - a report of eighteen cases. $\mathrm{Br}$ J Dermatol. 1975;92:363-73.

84. Gottlieb CC, Mishra A, Belliveau D, Green P, Heathcote JG. Ocular involvement in acute febrile neutrophilic dermatosis (Sweet syndrome): new cases and review of the literature. Surv Ophthalmol. 2008;53:219-26.

85. Ngan K, Leong JCY, Long H. Panuveitis in Sweet syndrome. Indian J Ophthalmol. 2020;68:2004-6.

86. Wang W, Wang X, Zhao H, Cui Y. A case report of sweet's syndrome with panuveitis and rhegmatogenous retinal detachment. Ocul Immunol Inflamm. 2021;29:1345-7.

87. Aghazadeh H, Sia D, Ehmann D. Central retinal artery occlusion associated with Sweet syndrome. Can J Ophthalmol. 2021;56:e103-5.

88. Guzmán-Almagro E, Fernández-Hortelano A, Díaz-Menéndez A, González-Martín-Moro J. Ocular involvement in a patient with 
Sweet syndrome: report of a case and review of the literature. Arch Soc Esp Oftalmol (Engl Ed). 2020;95:550-4.

89. Güemes-Villahoz N, Rodríguez-Quet O, Díaz-Valle D. Acute exaggerated meibomitis as initial manifestation of Sweet syndrome. Ophthalmology. 2020;127:1036.

90. Mishra AV, Fung AT, Pollmann AS, Henderson R, Shields C, Gupta RR. Relentlessly progressive sweet syndrome of the eye with scleritis and choroidal infiltration. Ocul Immunol Inflamm. 2020;1-5. https://doi.org/10.1080/09273948.2020.1788611.

91. Ramsey AL, Wallace WD, Abtin F, Suh JD, Liang LL, Shah S, et al. Sweet's Syndrome: A First in Human Lung Transplantation. Chest. 2021;160:e173-6.

92. Manglani R, Jilani N, Raji M, Epelbaum O. Pulmonary involvement in Sweet's syndrome. Am J Respir Crit Care Med. 2021;204(10):1222-3.

93. Mizes A, Khosravi H, Bordelon J, Kazlouskaya V, Karunamurthy A, Ho J, et al. Sweet syndrome with pulmonary involvement in a patient with myelodysplastic syndrome. Dermatol Online J. 2020;26:13030/qt1n73f6k5.

94. Mehrtens SH, Hasan ZU, Halpern SM, Mclornan DP. Sweet's syndrome with pulmonary involvement. BMJ Case Rep. 2019;12:e229997.

95. Stiller RH, Gadzhiev M, Schachtel AK, Chang OH, Bastawrous $\mathrm{S}$, Hermes Shantz H, et al. A 68-year-old man with skin rash and a pleural effusion. Chest. 2020;158:e33-6.

96. You YS, Park SW, Yun SK, Lee EJ. Bilateral sudden sensorineural hearing loss with Sweet syndrome: a case report. Medicine (Baltimore). 2020;99:e22127.

97. Walker BA, Stull LB, Hines JP. A sweet voice: acute febrile neutrophilic dermatosis of the larynx. Ear Nose Throat $\mathrm{J}$. 2021;1455613211022098. https://doi.org/10.1177/0145561321 1022098 .

98. Graça-Santos L, Kieselova K, Montenegro-Sá F, Guardado J, Morais J. Myocardial involvement in sweet syndrome: a rare finding in a rare condition. Arq Bras Cardiol. 2020;115:6-9.

99. Shimagaki H, Kabata Y, Nakamura A, Takei S, Takei I, Kimura $\mathrm{K}$, et al. Neutrophilic myositis with Sweet's syndrome leading to rhabdomyolysis: a case report. J Dermatol. 2020;47:e415-7.

100. Inamadar AC, Adya KA. The rash with painful and erythematous nodules. Clin Dermatol. 2019;37:129-35.

101. Deutsch A, Jacobson M, McLellan BN. Cutaneous adult T-cell leukemia/lymphoma presenting as sweet syndrome. Acta Oncol. 2020;59:334-5.

102. Pawar M, Zawar V, Kumavat S. Borderline tuberculoid leprosy in erythema nodosum leprosum reaction mimicking sweet's syndrome. Actas Dermosifiliogr (Engl Ed). 2021;112:75-7.

103. Chavez-Alvarez S, Herz-Ruelas M, Ocampo-Candiani J, GomezFlores M. Type 2 leprosy reaction resembling Sweet syndrome: review of new and published cases. Australas J Dermatol. 2020;61:e234-7.

104. Savitha B, Sardana K, Kumari R, Khurana A, Sinha S, Sachdeva $\mathrm{S}$. Case report: rapid response to low-dose thalidomide in a case of severe steroid recalcitrant erythema nodosum leprosum. Am J Trop Med Hyg. 2021;106:51-3.

105. Quek CWN, Foong YW, Tan SK, Soh SY, Tan PL, Koh MJA. Leukemia cutis in a child with juvenile myelomonocytic leukemia presenting with Sweet syndrome-like lesions and a history of multiple juvenile xanthogranulomas. JAAD Case Rep. 2020;6:1138-40.

106. Hobbs LK, Carr PC, Gru AA, Flowers RH. Case and review: cutaneous involvement by chronic neutrophilic leukemia vs Sweet syndrome-a diagnostic dilemma. J Cutan Pathol. 2021;48:644-9.

107. Shimizu Y, Nakagawa Y, Kotobuki Y, Kimura K, Hagiya H, Katayama I. Case of Mycobacterium haemophilum infection presenting with Sweet's syndrome-like reactions. J Dermatol. 2019;46:e319-20.

108. Ha D-L, Shin K, Kim H-S, Ko H-C, Kim B-S, Kim M-B. A case of vesicobullous rheumatoid neutrophilic dermatosis. J Clin Rheumatol. 2021;27:e118-9.

109. Sirka CS, Rout AN, Sahu K. Secondary syphilis with polymorphous and sweet syndrome like lesions: a rare case report. Indian Dermatol Online J. 2020;11:409-12.

110. Sayeed S, Imtiaz A, Naz F. SAPHO syndrome in an adult male with ulcerative colitis. J Coll Physicians Surg Pak. 2019;29:671-3.

111. Garcia A, Asad U, Sturgeon A, Tarbox M. Ulcerated zosteriform nodules in adenocarcinoma of the colon. Proc (Bayl Univ Med Cent). 2020;33:637-8.

112. Kazmi SM, Pemmaraju N, Patel KP, Cohen PR, Daver N, Tran $\mathrm{KM}$, et al. Characteristics of Sweet syndrome in patients with acute myeloid leukemia. Clin Lymphoma Myeloma Leuk. 2015;15:358-63.

113. Berger T, Sherman S, Hayman L, Wolach O, Shacham-Abulafia A, Raanani P, et al. Skin biopsies in acute myeloid leukemia patients undergoing intensive chemotherapy are safe and effect patient management. Sci Rep. 2021;11:11940.

114. Merlant M, Lepelletier C, Battistella M, Vignon-Pennamen M-D, Duriez P, Moguelet P, et al. Acute myeloid leukemia and myelodysplastic syndrome-associated Sweet syndrome: a comparative multicenter retrospective study of 39 patients. J Am Acad Dermatol. 2021;84:838-40.

115. Kromer C, Schön MP, Buhl T. Sweet's syndrome as precursor of hairy cell leukemia. Dtsch Arztebl Int. 2020;117:176.

116. Shah PR, Scott G, Beck LA. Image Gallery: hairy-cell leukaemia presenting with Sweet syndrome. Br J Dermatol. 2019;180:e3.

117. Thebo U, Tummala S, Nassereddine S, Haroun F. An atypical presentation of Sweet's syndrome in a myelofibrosis patient. BMJ Case Rep. 2019;12:e228076.

118. Kelly L, Justine S, Brandon G, Sandra H, Gwyn R. Sweet syndrome with bitter outcomes in cervical cancer: a case report. Gynecol Oncol Rep. 2021;36:100749.

119. Lemaire CC, Portilho ALC, Pinheiro LV, Vivas RA, Britto M, Montenegro M, et al. Sweet syndrome as a paraneoplastic manifestation of cholangiocarcinoma: a case report. World J Clin Cases. 2020;8:4122-7.

120. Chirasuthat P, Triyangkulsri K, Rutnin S, Chanprapaph K, Vachiramon V. Cutaneous nontuberculous mycobacterial infection in Thailand: a 7-year retrospective review. Medicine (Baltimore). 2020;99:e19355.

121. Vithoosan S, Thanushah B, Piranavan P, Gamlaksha D, Karunatilake H, Jayanaga A. A rare case of Sweet syndrome secondary to melioidosis. BMC Dermatol. 2019;19:16.

122. Kiratikanon S, Thongwitokomarn $\mathrm{H}$, Chaiwarith R, Salee $\mathrm{P}$, Mahanupab P, Jamjanya S, et al. Sweet syndrome as a cutaneous manifestation in a patient with Erysipelothrix rhusiopathiae bacteremia: a case report. IDCases. 2021;24:e01148.

123. Fania L, Ruggeri S, Sordi D, Oliva A, Provini A, Ricci F, et al. Sweet syndrome following a positive Mantoux test due to pulmonary tuberculosis. Dermatol Ther. 2019;32:e12754.

124. Escanilla C, Goldman Y, Bobadilla F, Segovia L. Sweet syndrome associated with secondary nodular syphilis in an immunocompetent patient. An Bras Dermatol. 2021;96:319-23.

125. Mishal J, Viner I, Livoff A, Maayan S, Magen E. Sweet syndrome and secondary syphilis in a person with acute necrotizing tonsillitis. Case Rep Dermatol. 2021;13:216-21.

126. Sharma R, Johnson RH, Heidari A, Malerich M, Stull WR, Cobos E. Neutrophilic dermatosis in myelodysplastic syndrome and chronic active hepatitis C. J Investig Med High Impact Case Rep. 2021;9:23247096211037456. 
127. Mudroch SM, Rohan C, Conger NG, Lindholm DA. Sweet syndrome in an elderly man with well-controlled human immunodeficiency virus. Cureus. 2020;12:e10330.

128. Dong R-J, Huang S-Z, Upadhyay P, Shrestha S, Zhai Y-J, Li Y-Y. Thalidomide in the treatment of Sweet's syndrome and eosinophilic folliculitis associated with immune reconstitution inflammatory syndrome. Front Med (Lausanne). 2019;6:343.

129. Taşkın B, Vural S, Altuğ E, Demirkesen C, Kocatürk E, Çelebi İ, et al. Coronavirus 19 presenting with atypical Sweet's syndrome. J Eur Acad Dermatol Venereol. 2020;34:e534-5.

130. Berro S, Calas A, Sohier P, Darbord D, Dupin N. Sweet's syndrome three weeks after a severe COVID-19 infection: a case report. Acta Derm Venereol. 2021;101:00486.

131. Agharbi F-Z, Oqbani K, Allaoui A, Chikhaoui I, Chiheb S. Sweet syndrome in post-COVID-19 infection: a case report. Travel Med Infect Dis. 2021;44:102188

132. de Lima ÍMF, Ferraz CE, Gonçalves de Lima-Neto R, Takano DM. Case report: sweet syndrome in patients with sporotrichosis: a 10-case series. Am J Trop Med Hyg. 2020;103:2533-8.

133. Kaur M, King S, Fotouhie A, Zangeneh TT. Unusual presentations of coccidioidomycosis in conjunction with autoimmune syndromes: a literature review and case series. J Clin Rheumatol. 2020;26:e43-7

134. Yan G, Tan KB, Chandran NS, Chai L, Chew KL, Somani J, et al. Histoplasmosis presenting with Sweet's syndrome. Clin Microbiol Infect. 2020;26:795-6.

135. Matsuzawa Y, Adachi E, Takahashi A, Sato H, Lim LA, Komatsu $\mathrm{T}$, et al. Cytokine profile in Sweet's syndrome under the treatment of pulmonary toxoplasmosis complicated with myelodysplastic syndrome. Intern Med. 2019;58:2079-83.

136. Sulk M, Ehrchen J. Sweet syndrome in association with enterobiasis. J Dermatol. 2019;46:e106-7.

137. Okamoto M, Hayashi S, Ikegami T, Kaminaga T, Hamasaki Y, Igawa K. Development of Sweet's syndrome and the immunological finding of systemic lupus erythematosus during the course of mixed connective tissue disease. Int J Dermatol. 2021;60:e107-8.

138. Filippi F, Chessa MA, Patrizi A, Baraldi C, Ferrara F, Bardazzi F. Tocilizumab-induced sweet syndrome in a patient with polymyalgia rheumatica. Dermatol Pract Concept. 2020;10:e2020019.

139. Baliu-Piqué C, Nogués-Antich E, Cucurell-Palomas M, Grados D. Neutrophilic dermatosis of the hands (Sweet syndrome of the hands) associated with rheumatoid arthritis. Reumatol Clin (Engl Ed). 2019;15:372.

140. Paul P, Walker CP, Paul M, Dey D. Sweet's syndrome in a patient with seropositive rheumatoid arthritis after starting adalimumab: is sweet's syndrome related to rheumatoid arthritis or is it the paradoxical effect of adalimumab? Cureus. 2021;13:e16804.

141. Nousari Y, Wu BC, Valenzuela G. Successful use of baricitinib in the treatment of refractory rheumatoid arthritis-associated Sweet syndrome. Clin Exp Dermatol. 2021;46:1330-2.

142. Manzo C, Pollio N, Natale M. Sweet's syndrome following therapy with hydroxychloroquine in a patient affected with elderly-onset primary Sjogren's syndrome. Medicines (Basel). 2019;6:E111.

143. Das A, Burmeister R, Chhaya R, Eisenga B, Kumar A. Sweet syndrome in a patient with systemic lupus erythematosus. J Clin Rheumatol. 2020;26:e85-6.

144. Murphy K, Morrison L, McGOLDRICK J. Sweet syndrome in eosinophilic granulomatosis with polyangiitis. J Rheumatol. 2020;47:1031-2.

145. Goodwin J, Ives S, Hashmi H. Sweet syndrome and hashimoto thyroiditis: a case report and review of the literature. AACE Clin Case Rep. 2020;6:e179-82.

146. Cook QS, Zdanski CJ, Burkhart CN, Googe PB, Thompson P, Wu EY. Idiopathic, refractory Sweet's syndrome associated with common variable immunodeficiency: a case report and literature review. Curr Allergy Asthma Rep. 2019;19:32.

147. Kiratikanon S, Phinyo P, Rujiwetpongstorn R, Patumanond J, Tungphaisal V, Mahanupab P, et al. Adult-onset immunodeficiency due to anti-interferon-gamma autoantibody-associated Sweet syndrome: a distinctive entity. J Dermatol. 2021. https:// doi.org/10.1111/1346-8138.16202.

148. Giraudo F, Miraglia E, Garbi ML, Yantorno M, Maradeo MR, Correa GJ, et al. Prevalence of pyoderma gangrenosum and Sweet's syndrome in inflammatory bowel disease at a tertiary healthcare center. Rev Esp Enferm Dig. 2021;113:691-7.

149. Sleiman J, Hitawala AA, Cohen B, Falloon K, Simonson M, Click B, et al. Systematic review: Sweet syndrome associated with inflammatory bowel disease. J Crohns Colitis. 2021;15:1864-76.

150. Giannese D, Ferro F, Moriconi D, Bonadio AG, Elefante E, Egidi $\mathrm{MF}$, et al. Use of tocilizumab in amyloid a nephropathy associated with Sweet syndrome: a case report and literature review. CEN Case Rep. 2021;10:23-9.

151. Jain L, Meegada S. Sweet syndrome in a patient with hidradenitis suppurativa. Clin Case Rep. 2020;8:772-3.

152. Gkrouzman E, Chirch L, Lakshminarayanan S. Drug-induced Sweet syndrome in a man with sarcoidosis: are there any common mechanisms of pathogenesis? J Clin Rheumatol. 2019;25:e122-6.

153. Cohen PR, Kurzrock R. Sweet's syndrome: a review of current treatment options. Am J Clin Dermatol. 2002;3:117-31.

154. Cerejeira A, Amoedo P, Coelho AR, Silva R, Pedrosa A, Nogueira A, et al. Recurrent Sweet syndrome presenting in a figurate pattern in a patient with Fanconi anemia. Int J Dermatol. 2021.

155. Jeanfils S, Joly P, Young P, Le Corvaisier-Pieto C, Thomine E, Lauret P. Indomethacin treatment of eighteen patients with Sweet's syndrome. J Am Acad Dermatol. 1997;36:436-9.

156. Maillard H, Leclech C, Peria P, Avenel-Audran M, Verret JL. Colchicine for Sweet's syndrome. A study of 20 cases. Br J Dermatol. 1999;140:565-6.

157. Horio T, Imamura S, Danno K, Furukawa F, Ofuji S. Treatment of acute febrile neutrophilic dermatosis (Sweet's syndrome) with potassium iodide. Dermatologica. 1980;160:341-7.

158. Horio T, Danno K, Okamoto H, Miyachi Y, Imamura S. Potassium iodide in erythema nodosum and other erythematous dermatoses. J Am Acad Dermatol. 1983;9:77-81.

159. Rujiwetpongstorn R, Chuamanochan M, Tovanabutra N, Chaiwarith R, Chiewchanvit S. Efficacy of acitretin in the treatment of reactive neutrophilic dermatoses in adult-onset immunodeficiency due to interferon-gamma autoantibody. J Dermatol. 2020;47:563-8.

160. Hrin ML, Feldman SR, Huang WW. Dapsone as corticosteroidsparing therapy for Sweet syndrome. J Am Acad Dermatol. 2021;S0190-9622(21)00462-X. https://doi.org/10.1016/j.jaad. 2021.02.067.

161. Chiewchanvit S, Jamjanya S, Rattanathammethee T, Mahanupab P, Tovanabutra N, Chuamanochan M. Bullous Sweet syndrome in a patient with acute myeloid leukemia treated with midostaurin: rapid response to acitretin and colchicine-a case report. Dermatol Ther. 2021;e15171. https://doi.org/10.1111/ dth. 15171.

162. Calabrese L, Caldarola G, Peris K, De Simone C. Recalcitrant Sweet syndrome successfully treated with adalimumab. J Dtsch Dermatol Ges. 2021;19:122-4.

163. Patel AV, Jotwani PM, Sultan KS. Azathioprine-induced Sweet syndrome treated with infliximab. Am J Ther. 2019;26:e616-7.

164. Shahid Z, Kalayanamitra R, Patel R, Groff A, Jain R. Refractory sweet syndrome treated with anakinra. Cureus. 2019;11:e4536. 
165. de Risi-Pugliese T, Seksik P, Bouaziz J-D, Chasset F, Moguelet $\mathrm{P}$, Gornet J-M, et al. Ustekinumab treatment for neutrophilic dermatoses associated with Crohn's disease: a multicenter retrospective study. J Am Acad Dermatol. 2019;80:781-4.

166. Heath MS, Ortega-Loayza AG. Insights into the pathogenesis of Sweet's syndrome. Front Immunol. 2019;10:414.

167. Dubertret L, Lebreton C, Touraine R. Inhibition of neutrophil migration by etretinate and its main metabolite. Br J Dermatol. 1982;107:681-5.

168. Passet M, Lepelletier C, Vignon-Pennamen M-D, Chasset F, Hirsch P, Battistella M, et al. Next-generation sequencing in myeloid neoplasm-associated sweet's syndrome demonstrates clonal relation between malignant cells and skin-infiltrating neutrophils. J Invest Dermatol. 2020;140:1873-1876.e5.

169. Diehl S, Rincón M. The two faces of IL-6 on Th1/Th2 differentiation. Mol Immunol. 2002;39:531-6.

170. Damsker JM, Hansen AM, Caspi RR. Th1 and Th17 cells: adversaries and collaborators. Ann N Y Acad Sci. 2010;1183:211-21.

171. Brys AK, Cox SE. Early-onset sweet-like dermatitis after facial hyaluronic acid filler injection. Dermatol Surg. 2020;46:1759-61.

172. Flanagan KE, Krueger S, Amano S, Auerbach A, St John J, Deng A. Sweet syndrome with perifollicular involvement because of koebnerization from facial hair plucking. J Cutan Pathol. 2021;48:1189-92.

173. Eid E, Safi R, El Hasbani G, Aftimos V, Abbas O, Kibbi A-G, et al. Characterizing the presence of neutrophil extracellular traps in neutrophilic dermatoses. Exp Dermatol. 2021;30:988-94.

174. Walterscheid B, Nguyen J, Tarbox M, Eshak N. Clopidogrelinduced sweet syndrome: severe dermatological complication after percutaneous coronary intervention. Eur Heart $\mathbf{J}$. 2021;42:2610.

175. Mattis DM, Limova M, Mully T. Dapagliflozin-induced sweet syndrome. Cutis. 2019;104:E22-4.

176. Mohamed A. Enasidenib-induced Sweet syndrome with differentiation syndrome. Clin Case Rep. 2021;9:e04099.

177. Suyama T, Ito S, Shinagawa A. Ixazomib-induced Sweet's syndrome. Int J Hematol. 2020;111:161-2.

178. Yavaşoğlu İ, Bolaman Z. Sweet syndrome associated with ixazomib. Turk J Haematol. 2021;38:234-5.

179. Oka S, Ono K, Nohgawa M. Ixazomib-induced Sweet's syndrome. Leuk Lymphoma. 2019;60:3590-1.

180. Neely G, Fajre X, Cabrera R, Castro A. Lamotrigine-induced Sweet syndrome: possible new drug association. JAAD Case Rep. 2020;6:1009-11.

181. Cardoso D, Coelho A, Fernandes L, Matos LV, Serrano I, Miranda H, et al. Sweet's syndrome induced by aromatase inhibitor in the treatment of early breast cancer. Eur J Case Rep Intern Med. 2020;7:001435.

182. Zhang W, Wei S, Peng X, Xie S, Zeng K, Lai K. Proliferative Sweet syndrome associated with pregnancy and low-molecular-weight heparin sodium. Scand J Rheumatol. 2019;48:428-9.

183. Alkassis S, Rizwan A, Daoud L, Chi J. Midostaurin-induced Sweet syndrome in a patient with FLT3-ITD-positive AML. BMJ Case Rep. 2021;14:e243615.

184. Fustà-Novell X, Morgado-Carrasco D, García-Herrera A, BoschAmate X, Martí-Martí I, Carrera C. Palbociclib-induced histiocytoid Sweet syndrome. Clin Exp Dermatol. 2021;46:348-50.

185. Korkmaz M, Eryılmaz MK, Karaağaç M, Demirkıran A, Araz M, Artaç M. Pemetrexed-induced Sweet Syndrome: First case report in the medical literature. J Oncol Pharm Pract. 2021;27:1307-10.

186. Jiang M, Tran AK, Marshman G. A neutrophilic dermatosis following treatment of myelofibrosis with ruxolitinib: an emerging phenomenon? Australas J Dermatol. 2021;62:e607-9.

187. Majid I, Mearaj S. Sweet syndrome after Oxford-AstraZeneca COVID-19 vaccine (AZD1222) in an elderly female. Dermatol Ther. 2021;34:e15146.

188. Torrealba-Acosta G, Martin JC, Huttenbach Y, Garcia CR, Sohail MR, Agarwal SK, et al. Acute encephalitis, myoclonus and Sweet syndrome after mRNA-1273 vaccine. BMJ Case Rep. 2021;14:e243173.

189. Sechi A, Pierobon E, Pezzolo E, Germi L, Trevisan G, Zardo D, et al. Abrupt onset of Sweet syndrome, pityriasis rubra pilaris, pityriasis lichenoides et varioliformis acuta and erythema multiforme: unravelling a possible common trigger, the COVID-19 vaccine. Clin Exp Dermatol. 2021. https://doi.org/10.1111/ced. 14970.

190. Capassoni M, Ketabchi S, Cassisa A, Caramelli R, Molinu AA, Galluccio F, et al. AstraZeneca (AZD1222) COVID-19 vaccine-associated adverse drug event: a case report. J Med Virol. 2021;93:5718-20.

191. Darrigade A-S, Théophile H, Sanchez-Pena P, Milpied B, Colbert $\mathrm{M}$, Pedeboscq S, et al. Sweet syndrome induced by SARS-CoV-2 Pfizer-BioNTech mRNA vaccine. Allergy. 2021;76:3194-6.

192. Bürgler C, Vinay K, Häfliger S, Klötgen H-W, Yawalkar N. Infliximab reduces activated myeloid dendritic cells, different macrophage subsets and CXCR3-positive cells in granuloma annulare. J Dermatol. 2019;46:808-11. 